\title{
Negative Politeness in Korean Questions: Interaction \\ between Epistemic Uncertainty and Conventional \\ Indirectness"
}

Arum $\mathrm{Kang}^{\dagger}$

Korea University

\begin{abstract}
In this paper, I investigate the negative politeness phenomena in Korean question. The current study focuses on the examination of the mitigating effects raised from the epistemic modal marker $n k a$. Thus far, $n k a$ has been treated as a sub-type of question marker used in familiar speech style. Contrary to the previous view, however, I claim that $n k a$ should NOT be treated as a factual question marker; rather, it is an attenuative modal marker used as a pragmatic device for conventional indirectness. Since Korean speakers tend to consider speech act of question as an illocutionary act of requesting with a big favor, they use nka in order to minimize the threat and avoid the risk of losing face. In this vein, $n k a$ is employed for the pragmatic treatment of mitigated illocutionary force to smooth the conversational interaction. An important contribution of the current work is to add the discussion by considering novel empirical issues in Korean in which epistemic modal device can be another element that exhibits the mitigation in the illocutionary act of asking a question.
\end{abstract}

Keywords: (negative) politeness, question, epistemic modal, mitigator, conventional indirectness

\section{Introduction}

The purpose of this study is to identify the novel function of sentence ender $n k a$ occurring in question. Traditionally, from the semantico-pragmatic point of view, nka has a dual function as a marker of factual question and modalized non-factual question (Y Jang 1999; C Kim 2010; HJ Koo and S Rhee 2013b; A Kang 2015; A Kang and S Yoon, to appear, a.o.). As shown in (1), when nka behaves as a factual question, the speaker Jack asks to the hearer John whether he is the winner or not; whereas, in (2), the modalized non-factual nka-question does not expect such a

\footnotetext{
* I am very grateful to three anonymous reviewers for their valuable comments, suggestions and useful insights. I am responsible for any remaining errors.

† Corresponding author: arkang@korea.ac.kr
} 
response. Indicated in the translation as maybe $\cdots$ or maybe not, nka in modalized question expresses speaker's epistemic uncertainty (adapted from A Kang and S Yoon, to appear, (4)):

(1) Context: Jack, a senior reporter, was waiting for two college students, John and Bill, who were competing for the win in the finals of the college chess competition. He was ready to interview Bill, because Jack was told from her boss that Bill was the strong front runner of the competition. After the match, John and Bill came out of the room. John had a very subtle smile and Bill had a poker face. Given their facial expressions, Jack infers that John might have won. But at the same time, John is unlikely to be the winner given his boss's comment. With full of uncertainty about his inference,

a. Jack asks John:

caney-ka wusungca-(i)-nka? [factual question]
you $_{(+\mathrm{Pol})}-\mathrm{Nom}$ winner-be-NKA

'Are you the winner?'

b. Jack talks to himself:

con-i wusungca-(i)-nka? [modalized non-factual question]
John-Nom winner-be-NKA
'Maybe John is the winner, maybe not?'

As a factual question marker, the behavior of $n k a$ has been characterized in terms of speech style which is deeply related with the notion of honorification and politeness. Simply put, honorifics are devices "as grammatical and lexical forms encoding the speaker's socio-culturally appropriate regard towards the addressee (i.e., addressee honorification) and the referent (i.e., referent honorification)" (H-M Sohn 1999, p.408). On the other hand, politeness is defined as a result of a speaker's cognitive assessment of the social context (Holtgraves 2013). It is expressed in a good manner in order to reduce the "face threat" (Brown and Levinson 1978, 1987) and show positive concerns to the hearer. Traditionally it has been argued that there be a clear distinction between the realm of honorific and polite utterance; they are separate since only honorification depends on social convention or obligation (H-r Hwang 1975, 1990; Dredge 1983; H-M Sohn 1986). However, there has been a recent trend which perceives them to be tied up with each other in Korean culture under the larger concept of 'showing respect' and 'maintaining social hierarchies.'

This holds true in the case of speech levels. Korean speech style system is the form encoding the index of the relationship between the speaker and the hearer. As 
shown in the following interrogatives, the different sociocultural index (i.e., honorific relation) is reflected in the distinct choice of six different types of verb endings along the politeness continuum:1)

(2) Interrogative speech levels in the contemporary Korean (adapted from H-M Sohn 1999, 2013)
a. ney-ka
you-Nom winner-be-Q?
wusungca-(i)-ni?
[plain style; low politeness]
b. ney-ka wusungca-i-a?
you-Nom winner-be-Int?
[intimate style; low politeness]
c. caney-ka wusungca-(i)-nka?
you-Nom winner-be-NKA
d. tangsin-i wusungca-i-o?
you-Nom winner-be-Bln?
e. tangsin-i wusungca-i-e.yo?
you-Nom winner-be-Pol?
f. tangsin-i wusungca-(i)-pnikka? [deferential style; high politeness] you-Nom winner-be-Q?
'Are you the winner?'

Among those speech levels, $n k a$ in (2c) has been argued as a familiar speech style ender, and its politeness force is not high but neutral. It is due to the reason that, unlike polite speech style ending yo in (2e), the relation indexed by $n k a$ is not superior; for example, $n k a$ can be used by a male adult to an adolescent (e.g. a high school or college student), or between two close adult friends whose friendship began in adolescence (H-M Sohn 2013).

Given the above examples from (1) to (2) as our background data, consider the following data as our starting point. The question in (3) is felicitously uttered in which nka can co-occur with yo:
(3) tangsin-i
wusungca-(i)-nka-yo?
you-NOM
winner-be-NKA-Pol

'Are you the winner?'

\footnotetext{
1) Different scholars label Korean speech levels differently between four to six levels. Current study follows H-M Sohn (1999, 2013)'s six categorizations.
} 
Importantly, the above example reveals three important characteristics of $n k a$ : First, when $n k a$ and yo co-occurs, nka loses its modal effect of epistemic uncertainty in (1b), but it gives rise to factual-question interpretation. Second, the sociocultural index or politeness level of $n k a$ is not lexically fixed. It would be hard to consider that nka-yo in (3) has yo in (2e) as its polite level counterpart. Its empirical motivation comes from the fact that, if we assume that it has a fixed value, we cannot account for the reason why $n k a$ with neutral politeness value can co-occur with high value of $y o$. Third, Korean native speakers would judge sentence ended with nka-yo in (3) as being more indirect with soft illocution than the sentence merely ended with yo.

The discussion crucially hinges on the question which semantico-pragmatic category of $n k a$ ought to be distinguished within the traditional domain of politeness and how they ought to be defined. This, accordingly, brings us to the following main question of the present study: should we treat multiple varieties of $n k a$ into familiar vs. polite speech level endings or analyze it in a unified way? While it has been previously recognized that the interpretation of nka-yo as a mitigating sentence ender (S Chang 2014, a.o.), the exact nature of the mitigating effect involved has not been properly understood. Rather than considering multi-functional aspects, the current study provides a unified analysis for the distinct reading of $n k a$ in (2c) and (3) as a politeness mitigator. The function of $n k a$ occurring in question involves the pragmatic strategy of politeness. Specifically, I offer an analysis of nka as an attenuative modal marker. Further, as will become clear in Section 3, the pragmatic mitigating role of $n k a$ comes from its semantic function as an epistemic modal operator (A Kang 2015; A Kang and S Yoon, to appear). By doing this, nka encodes the negative politeness (Levinson and Brown 1987) stance about the propositions being uttered. I suggest it is due to the reason that Korean speakers tend to recognize interrogative speech act as a type of request requiring for an answer with high demand. In order to reduce face-threatening of such a request, speakers employ $n k a$ as a pragmatic device for conventional indirectness. A further support comes from the conceptual link between modalized non-factual question and polite factual question under the process of grammaticalization of stance marker (S Rhee 2011) and subjectification (Traugott 1982, 1986).

In what follows, I begin Section 2 by reviewing the approach to politeness in the sense of Brown and Levinson (1987). I further introduce previous literature on Korean politeness by means of epistemic modal marker keyss. Section 3 provides core properties of $n k a$ as a politeness marker. In Section 4, I lay out an attenuative modal analysis of conventional indirectness. Some remaining issues regarding co-occurrence 
with honorific morphemes are discussed in section 5. I conclude with section 6 .

\section{Theoretical Background on Politeness}

\subsection{Brown and Levinson (1987)}

Brown and Levinson's $(1978,1987)$ model of politeness is based on the notion of "face" as one's public self-image which is expected to be respected. When the speaker commits an act which potentially causes the hearer to lose face, described as a face threatening act (FTA, henceforth), the speaker will use a politeness strategy in order to minimize the risk. There are two main constituents of politeness: 'negative politeness' and 'positive politeness'. Positive politeness is used to satisfy the speaker's need of approval and belonging whereas negative politeness is used to minimize an imposition. Conventional indirectness is one of the negative strategies such as questioning, hedging, minimizing imposition, giving deference and apologizing. ${ }^{2)}$

Brown and Levinson proposed the formula for calculating the weight of an FTA, as in (4). The speaker evaluates the weightiness or seriousness of an FTA(x) on the basis of the following three factors: the first factor is social distance which represents a symmetric social dimension between the speaker $(\mathrm{S})$ and the hearer $(\mathrm{H})$. The second factor is a measure of the power, which represents an asymmetric social dimension of relative power that the hearer has over the speaker. The third factor is the absolute ranking of impositions which refers to the importance or degree of

2) Negative politeness strategies (adapted from Brown and Levinson 1987):

\begin{tabular}{|c|c|}
\hline Negative politeness strategy & Linguistic politeness type \\
\hline Don't presume/assume & 1. Question, hedge \\
\hline Give $\mathrm{H}$ option not to do act & 2. Be pessimistic \\
\hline \multirow[t]{2}{*}{ Minimize threat } & 3. Minimize the imposition \\
\hline & 4. Give deference \\
\hline Communicate S's want to not impinge on $\mathrm{H}$ & 5. Apologize \\
\hline Be direct + Give $\mathrm{H}$ options & 6. Be conventionally indirect \\
\hline \multirow[t]{3}{*}{ Dissociate $\mathrm{S}, \mathrm{H}$ from the particular infringement } & $\begin{array}{l}\text { 7. Impersonalize } \mathrm{S} \text { and } \mathrm{H} \text { : Avoid the pronouns } \\
\text { 'I' and 'you' }\end{array}$ \\
\hline & 8. State the FTA as a general rule \\
\hline & 9. Nominalize \\
\hline $\begin{array}{l}\text { Redress other wants of H's, derivative from } \\
\text { negative face }\end{array}$ & $\begin{array}{l}\text { 10. Go on record as incurring a debt, or as not } \\
\text { indebting } \mathrm{H}\end{array}$ \\
\hline
\end{tabular}


difficulty in the situation:

(4) Weightiness $(x)=\operatorname{Distance}(\mathrm{S}, \mathrm{H})+\operatorname{Power}(\mathrm{H}, \mathrm{S})+$ Rank of imposition $(x)$

If the speaker asks for a big favor in requests, a large rank of imposition would occur. Such high ranks of imposition are liable to require more formal and polite structures. Brown and Levinson assert that the variable of rank of imposition is culturally dependent since each culture differently classify acts according to their degree of imposition. As will become clear below, I claim that Korean speakers tend to impose high rank on the questioning since in Korean culture, they consider the speech act of asking a question is regarded as the illocutionary act of requesting with a big favor. In this vein, as a strategy of negative politeness, the mitigator $n k a$ is employed in order to minimize the imposition on question.

\subsection{Politeness marked by modal marker as a mitigator}

The linguistic expression of politeness can be achieved by making one's statement indirect. Previously mentioned in Section 2.1 , it is generally assumed that the pragmalinguistic resources and the illocutionary force for an indirect request vary crosslinguistically. In order to soften direct request, for example, languages employ various types of mitigators which comprise both lexical (e.g., diminutives such as please, mental verbs such as think/ believe) and syntactic (e.g., conditional, imperfect) devices (Faerch and Kasper 1989).

In Korean, the indirect expressions for politeness have been discussed in the area of speech acts such as making requests, apology and responses (Blum-Kulka 1987; J Lee 1999; Márquez-Reiter 2002; Byon 2006; Hatfield and J-W Hahn 2011, a.o.). Recently, the specific use of indirect linguistic devices have been widely discussed in terms of attenuative modal marking (H-M Sohn 1999, 2013; S Rhee 2011, a.o.). Particularly, the interactions between politeness and epistemic modal marker keyss occurring in imperatives have been received much attention (H-Y Jeon 2004; J-Y Bak 2006; J Jeong 2013, a.o.). When epistemic modal keyss is used in imperatives, it contributes the pragmatic effect of politeness. The mechanism is as follows: although the speaker does not have epistemic uncertainty on the given situation, she intentionally decides to express their speech act as being "uncertain" due to the reason that they want to lesson the hearer's imposition. As a result, the role of mitigator for indirectness is achieved. Following examples show the degree of 
politeness under the situation where the speaker makes a request to take care of her baby (J Jeong 2013: (3), (5), (9)):

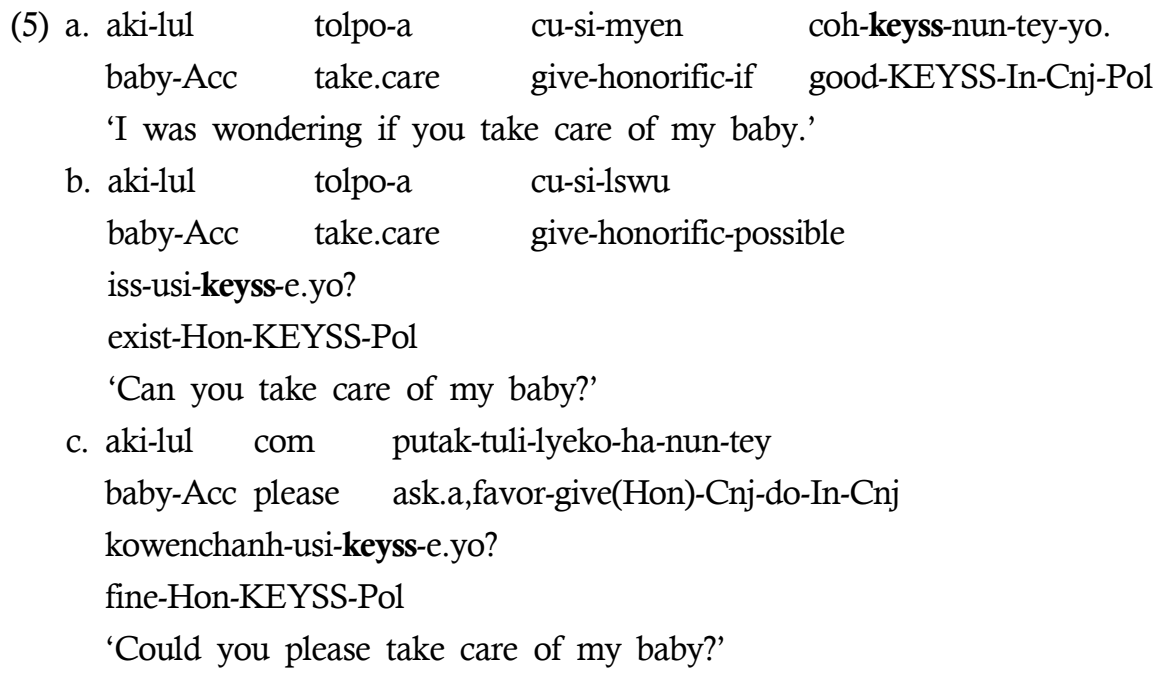

Among the three, (5a) is the most direct and least polite; whereas (5c) is the least direct and most polite.

\section{Core Properties of nka}

\subsection{Epistemic modal $n k a$ as a nonveridical equilibrium}

Before jumping into the main discussion, in this section, I will briefly introduce the previous analysis on the semantic function as epistemic possibility modal $n k a$. Traditionally, it has been considered that the non-factual question marker nka indicates the speaker's uncertainty or non-commitment to the truth of the proposition, just like an epistemic modal. In this sense, the nka-question has been termed as a Modalized Question (MQ, henceforth) (A Kang 2015; A Kang and S Yoon, to appear). The infelicity in (6a) confirms the modality in nka-questions; when the question concerns the addressee, using nka becomes infelicitous. The oddity arises because the second person subject ney 'you' (i.e., the hearer, John) would know if he is the winner or not. Note the contrast with the factual question marker $n i$ in (6b) which forms a hearer-addressed question requiring an answer from the hearer. 
(6) Context: same as in (1). Jack asks John:
a. \#ney-ka wusungca-i-nka?
[Modalized question]
you-Nom winner-be-NKA
'lit. \#(I am asking you whether) maybe you are the winner, maybe not?'
b. ney-ka wusungca-i-ni? [Ordinary question]
you-Nom winner-be-Q
'Are you the winner?'

The infelicity in (6a) reveals that the nka-question does not require a hearer's response but only conveys the speaker's uncertainty. Given this, nka has been posited as a separate type of question from ordinary questions. With the speaker's consideration of a set of alternatives, a MQ questions the speaker's belief and knowledge and expresses her weakest commitment to the possibility of proposition in question.

A Kang and S Yoon (to appear) suggests that the meaning of $n k a$ can be captured under the framework of nonveridical equilibrium (Giannakidou 2013; Giannakidou and Mari, to appear). The following is the brief sketch on the notion of (non)veridicality. Regarding the veridicality assessment, Giannakidou (1995 et seq.) argues that it relies on the belief and knowledge of the epistemic agent, i.e., the person assessing a proposition. Every sentence is evaluated with respect to an agent's epistemic state, which is called information state. Information state is understood as a set of worlds, representing what the epistemic agent $i$ knows or believes. She notes that truth in a model is relativized with respect to an epistemic model, in which a proposition $p$ is always true or false with respect to an individual $x$. Accordingly, this information state is termed a model of the individual. The proposition $p$ of a main assertion is evaluated in the epistemic subject's model:

(7) Epistemic model of an individual $i$ (Giannakidou 1999: (45))

An epistemic model $\mathrm{M}(i) \in \mathrm{M}$ is a set of worlds associated with an individual $i$ representing worlds compatible with what $i$ believes or knows.

(8) Truth in an epistemic model (= full commitment) (Giannakidou 2013: (8)(9)) A proposition $p$ is true in an epistemic model $\mathrm{M}(i)$ iff $\mathrm{M}(i) \subseteq p: \forall \mathrm{w}[\mathrm{w} \in \mathrm{M}(i)$ $\left.\rightarrow \mathrm{w} \in\left\{\mathrm{w}^{\prime} \mid p\left(\mathrm{w}^{\prime}\right)\right\}\right]$

a. John won the race. 
b. $\llbracket$ John won the race $\rrbracket^{M}=1$ iff $\forall \mathrm{w}\left[\mathrm{w} \in \mathrm{M}\right.$ (speaker) $\rightarrow \mathrm{w} \in\left\{\mathrm{w}^{\prime} \mid\right.$ John won the race in $\left.\left.\mathrm{w}^{\prime}\right\}\right]$

According to the definition, an unembedded positive assertion in the simple past like (8a) is veridical because the indicative assumes the speaker's commitment by default. Nonveridicality, on the other hand, is a function indicating the non-commitment to the truth of a proposition, shown as follows:

(9) (Non)veridicality and (non)homogeneity (Giannakidou 2013: (13)):

a. An information state (a set of worlds) $\mathrm{W}(i)$ relative to an epistemic agent $i$ is veridical with respect to a proposition $p$ iff all worlds in $\mathrm{W}(i)$ are $p$-worlds. (Positively homogeneous state).

b. An information state $\mathrm{W}(i)$ relative to an epistemic agent $i$ is nonveridical with respect to a proposition $p$ iff $\mathrm{W}(i)$ is partitioned into $p$ and are $\neg p$ worlds. (Non-homogeneous state).

According to Giannakidou, nonveridical operators include disjunctions and questions. In this vein, $n k a-\mathrm{MQ}$ is nonveridical in that $\mathrm{MQ}$ indicates an equal possibility of $p$ and $\neg p$ worlds given what the speaker's doxastic world is. The effect of maximal weak commitment of $n k a-\mathrm{MQs}$ is achieved with the formation of non-homogenous nonveridical states partitioned in equipoised epistemic spaces. The state of equilibrium in the modal base is represented as follows (A Kang and S Yoon, to appear, (56)):

(10) Nonveridical equilibrium of $n k a-\mathrm{MQ}: 3)$

$\llbracket \operatorname{NKA} \operatorname{MODAL}(p) \rrbracket^{o, M, i, S}$ will be defined iff

a. the modal base $\mathrm{M}(i)$ is nonveridical;

b. $\llbracket \operatorname{NKA} \operatorname{MODAL}(p) \rrbracket^{O, M, i, S}=1$ iff $O$ is empty; and

c. $\exists \mathrm{w}^{\prime} \in \mathrm{M}(i) \mathrm{p}\left(w^{\prime}\right)$

3) The modal structure under the framework of nonveridicality involves the following three main ingredients (Giannakidou and Mari, to appear):

(i) a. a nonveridical modal base $\mathrm{M}(i)$

b. a secondary modal base $S$

c. a meta evaluation 0

I skip the relevant discussions for reasons of space. Refer to A Kang and S Yoon (to appear) for details. 
Further empirical evidence to support the status of epistemic modal force comes from the fact that $n k a$ exhibits distributional restrictions with polite and deferential speech style endings. As shown below, it co-occurs with polite speech ending $y$, not with deferential style ending supnikka. It is due to the reason that informal styles (i.e., yo) always keep the same shape regardless of sentence type, freely occur with modality markers, whereas formal style (i.e., supnikka) cannot (Brown 2015):

(11) a. tangsin-i wusungca-(i)-nka-yo?

you-Nom winner-be-NKA-Pol

b. *tangsin-i wusungca-(i)-nka-pnikka?

you-Nom winner-be-NKA-Q

'Are you the winner?'

\subsection{Politeness from historical reanalysis}

Crosslinguistically, employing modal device as a negative politeness is further evidenced by their observation of similarities in the linguistic strategies employed by speakers of different languages. Among them, Japanese case seems to be quite equivalent to Korean. Japanese employs two distinct lexical items, the epistemic modal darou and its polite form deshoo. By using darou, Japanese speakers form a self-addressed (i.e. non-factual) question just like $n k a$, whereas by using deshoo in (13), they make a polite factual question, such as a quiz show a situation like that in (14) (Hara and Davis 2013: (24)):

(12) $Y$

$\begin{array}{llll}\text { Yurie-wa } & \text { wain-o } & \text { nomu } & \text { darou-ka } \downarrow \\ \text { Yurie-TOP } & \text { wine-ACC } & \text { drink } & \text { DAROU-Q }\end{array}$

'I wonder if Yurie drinks wine.'

(13)
Doitsu-no
shuto-wa
doko
deshoo-ka
[Japanese]
Germany-GEN capital-TOP where DAROU.POLITE-Q
'Where is the capital of Germany?'

I propose for them are highly similar in a way that there exists a strong connection between the dual use of modalized non-factual question and polite factual question, as follows: 
(14) a. darou-ka $\approx n k a$

b. deshoo-ka $\approx$ nka-yo

The connection between modal markers and politeness has been documented in the past, and is based on the idea that polite attenuative forms arise from modal markers encoding speaker's epistemic stance through a process of historical reanalysis. $S$ Rhee (2011) explains the grammaticalization of the path from ignorance modal to attenuative in order to encode speaker's politeness stance about the proposition. $\mathrm{He}$ shows grammaticalization as in (15). The following chains of politeness reveals the path of modal markers developed into conjecturals en route (cf. universal path: Bybee et al. 1994), as shown below (S Rhee 2011: (22)):

(15) Grammaticalization chains of politeness in modal markers ignorance $\rightarrow$ conjecture $\rightarrow$ attenuative

Related to this, it leads us to prediction that one interesting consequence of the historical change from non-veridical equilibrium operator to politeness marker would be that $n k a$ may give rise to politeness attitude. That said, this politeness of $n k a$ may have undergone the process of "subjectification" (Traugott 1982, 1986; Traugott and Dasher 2002). Subjectification is a subtype of grammaticalization which can be best characterized as its meaning change. On its path of process, Traugott (1986: 540) puts, "meaning tend to come to refer less to objective situations and more to subjective ones (including speaker point of view), less to the described situation and more to the discourse situation". In this vein, I argue that $n k a$ is selected to encode the subjectivity stance of the speaker. By employing the speaker's epistemic ignorance, the speaker exhibits an uncertain attitude for the purpose of softening the hearer's imposition. Expressing speaker's epistemic uncertainty on the proposition increase the degree of politeness, because it emphasize the speaker's ignorance hence the necessity of begging the answer.

\subsection{Politeness harmony}

Another piece of empirical evidence for politeness effect comes from its compatibility with other politeness markers. As shown in (16) below, the double occurrence of speech style endings should be harmonic and of compatible force in terms of politeness. Accordingly, the politeness marker yo can co-occur with the deferential 
style ending pnikka in (16f) whereas it is not allowed to co-occur with the plain style ending $n i$ in (16a) and blunt style ending $o$ (16d). Interestingly, yo can co-occurs with $n k a$ in (16c) which was raised as our original puzzle:
(16) a. *ney-ka wusungca-(i)-ni-yo?
[politeness clash]
you-Nom winner-be-Q-Pol?
b. tangsin-i wusungca-i-e.yo?
you-Nom winner-be-Pol?
c. tangsin-i wusungca-(i)-nka-yo? [politeness harmony] you-Nom winner-be-NKA-Pol
d. *tangsin-i wusungca-i-o-yo? [politeness clash] you-Nom winner-be-Bln-Pol?
f. tangsin-i wusungca-(i)-pnikka-yo? [politeness harmony] you-Nom winner-be-Q-Pol?
'Are you the winner?'

The above empirical data leads us to assume that the multiple exponents of politeness are not pragmatically redundant, but have their own politeness force. In order to make iterated politeness markers have a harmony, nka and yo are of compatible force. Although $n k a$ lacks [+Hon], i.e., the feature of higher social ranking indexing, it still plays a role as a mitigating ender. Having high value in the factors of politeness weightiness, $n k a$ fortifies the politeness of given proposition. Thus $n k a$ is well suited to $y o$, which reveals incompatibility with other non-politeness markers.

Thus far, we have observed the empirical evidence for an nonveridical equilibrium vs. politeness split by showing that the pragmatic contribution of epistemic modal operator $n k a$ deeply affects politeness. Now that we are ready to propose the role of politeness $n k a$, in the next section, let's explore the basic assumption of the conventional indirectness induced by $n k a$.

\section{Analysis}

In line with Brown and Levinson (1978, 1987), I will now present my own analysis of Korean politeness marker $n k a$ occurring in question. It has been noted that speech acts make two-way distinction into assertion and suggestion. And suggestion is further subdivided into direction (i.e., request) and question. From Searle (1975), the 
speech act of asking a question has been considered as a special case of the illocutionary act of requesting, given that the purpose of asking a question is to encode a speaker's wish to have common ground between interlocutors in terms of true answer.

As I already mentioned in Section 2, the form of linguistic expression of politeness varies with grammatical structure and cultural variables. Thus it leads us to hypothesize that there is a cultural-specific valuation for the three variables of politeness weightiness, distance, power and rank of imposition. Each of these factors interacts each other and differently relates to the politeness of communication. Especially, rank of Imposition is also a very important clue in helping speakers select the appropriate language strategies to perform a request. This means that the bigger the request is, the more polite one must be.

Likewise, Korean carries its own politeness orientation and have its own way of expressing close/long distance, high/low power relationship and large/small rank of imposition. Korean has its cultural-specific valuation on question which is treated as a serious request for a big favor. Asking a direct question appear to be inherently impolite and face-threatening because they intrude in the hearer's territory. In order to minimize the threat and avoid the risk of losing face, by using nka, Korean speakers prefer for indirectness and issuing the request to smooth the conversational interaction.

As shown in the differently weighted politeness variables below in (17), we assume that when situation involve a hearer of higher status, distance (D) and power (P) are assigned markedly high values, and the polite speech style ender yo is used in (17a). On the other hand, the use of $n k a$ in (17b) does not implies such a higher status of hearer. When the speaker talks to younger generation or close friend, (s)he sees no risk of damaging hearer's face in terms of power. So it does not have to assign power a high value. Rather, it increases the values of distance and imposition as shown. Thus even though the degree of power is default (or low) in this situation, the assessment of $\mathrm{W}(\mathrm{x})$ will become high. In other words, distance and rank of imposition are given high values for $n k a$, which elevates the value of the weightiness of the FTA. This high $\mathrm{W}(\mathrm{x})$ value calls for the function of $n k a$ as a mitigator, which I claim to be a negative politeness strategy. Importantly, yo does not assign such a high value on the imposition. When yo and $n k a$ co-occurs in (17c), distance, power and imposition are allocated high value. As a result, the total weightiness of politeness gets fortified: 
(17) Politeness weightiness and variables in Korean question

$\begin{array}{lccc} & \mathrm{D}(\mathrm{S}, \mathrm{H}) & \mathrm{P}(\mathrm{H}, \mathrm{S}) & \mathrm{R} . \mathrm{I}(\mathrm{x}) \\ \text { a. } y o & + & + & \varnothing \\ \text { b. } n k a & + & \varnothing & + \\ \text { c. } n k a-y o & ++ & + & +\end{array}$

Despite of distinct power values between $y o$ and $n k a$, they are compatible since they are harmonious in high $\mathrm{W}(\mathrm{x})$ value, which I previously termed politeness concord in Section 3.3.

Again, the imposition of question is considered more serious than other speech acts. Koreans treat question as highly imposing act of request, so it demand more redress to mitigate its increased threat level. In order to decrease the treat, epistemic modal marker $n k a$ is strategically used as a mitigator. In this sense, Korean would be a distinct language in which the degree of politeness in question is varied depending on the power and rank of imposition.

Further, the split politeness expressions in Korean question support the dichotomy of politeness divided into normative politeness (i.e., obligatorily) and strategic (i.e., optionally) politeness, suggested by H-M Sohn $(1999,2013)$. Sohn asserts that honorifics are the grammatically and lexically encoded forms of normative (i.e. obligatory) politeness in which social indexing is expressed. The function of polite speech style ender yo is equivalent to the normative politeness marker in (18a), and $n k a$ to the strategic politeness marker in (18b). In (18c), normative and strategic politeness markers are iterated, and they strengthen politeness degree.

(18) Distinct types of politeness in Korean question
a. tangsin-i wusungca-i-e.yo? [indirect, polite (normative)] you-NOM winner-be-Pol
b. caney-ka wusungca-(i)-nka? [indirect (strategic)] you-Nom winner-be-NKA
c. tangsin-i wusungca-(i)-nka-yo? [indirect, polite (normative+strategic)] you-NOM winner-be-NKA-Pol
'Are you the winner?'

Thus far, I examined the notions of indirectness and politeness in the speech act of question by showing that there is a close corelation between conventional indirectness and politeness in Korean. It was found that conventional indirectness 
marked by $n k a$ was the common means of requesting for an answer in situations which display high rank of imposition value.

\section{Remaining Issues: Co-occurrence with Honorific Morphemes}

When honorific expressions are considered as normative politeness as I showed in the previous section, nka would be freely compatible with honorific morphemes. This is well evidenced by the following example. As shown in (19), the sentence contains caney $($ Lit. $=$ you $)$, a $2^{\text {nd }}$ pronoun with positive value of politeness. At first glance, the data seems puzzling: although the subject caney is negative honorific value, the sentence can contain a verbal honorific morpheme -si-. Given that Korean honorifics display subject-verb agreement, one would expect that the sentence is infelicitous. However, it is not the case. It is due to the reason that, I claim, as an honorific morpheme, si- shares a high $\mathrm{W}(\mathrm{x})$ value which makes it compatible with $n k a$ under the condition of politeness harmony. Accordingly, the force of politeness is reinforced:

(19)

$\begin{array}{lccl}\text { caney-nun } & \text { cenyek } & \text { siksa-lul } & \text { ha-si-ess-nu-nka? } \\ \text { You }_{(+\mathrm{Pol})}-\mathrm{Top} & \text { evening } & \text { meal-Acc } & \text { do-Hon-Past-IN-NKA } \\ \text { 'Had you }(+\mathrm{Pol}) & \text { have your evening meal?' } & \end{array}$

Likewise, the sentence (20) is felicitous. It displays subject-verb honorific agreement, and that nominative case marker kkeyse also agrees with the subject DP/NP sensayngsim.

(20) sensayngnim-kkeyse-nun

$\mathrm{You}_{(+\mathrm{Hon})}-\mathrm{Hon}-\mathrm{Top}$

ha-si-ess-nu-nka-yo?

do-Hon-Past-IN-NKA-Pol

'Had you $_{(+H o n)}$ have your evening meal?' cenyek siksa-lul

evening meal-Acc

However, the story seems not that simple. Although the polite marker yo does not appear in the following examples in (21), honorific agreement is well observed with -si- and kkese. But they are infelicitous and politeness harmony cannot property capture the reason: 
(21) a. \#caney-kkeyse-nun

$\mathrm{You}_{(+\mathrm{Pol})-\mathrm{Hon}-\mathrm{Top}}$

ha-si-ess-nu-nka?

do-Hon-Past-IN-NKA

'Had you $_{(+\mathrm{Hon})}$ have your evening meal?'

b. \#sensayngnim-kkeyse-nun

cenyek siksa-lul

$\mathrm{You}_{(+\mathrm{Hon})}-\mathrm{Hon}-\mathrm{Top}$

ha-si-ess-nu-nka?

do-Hon-Past-IN-NKA

'Had you have your evening meal?' cenyek siksa-lul

evening meal-Acc

In order to see the full picture of the co-occurrence of honorific morphemes and $n k a$, detailed analysis of the strategy types is another worthwhile topic for further investigation.

\section{Conclusion}

In this paper, I examined the link between politeness and conventional indirectness in Korean, through the analysis of epistemic modal marker nka occurring in question. I have shown that Korean language has a cultural-specific valuation for questioning: the speakers consider speech act of asking a question as highly imposing act of request, which makes a strategical use of nonveridical equilibrium operator $n k a$ as a pragmatic mitigator to smooth the communication acts. Current study has the following important theoretical implication: first, there exists the interrelated realm of politeness and honorifics in Korean. Second, regarding lexical politeness devices, all honorific expressions seem to be polite expressions, not vice versa. In this sense, the domain of honorification entails politeness.

In the future work, I will have to address several questions raised by polite question. First, what is the affinity between epistemic modal and polite question such that this polysemy is found across language? Second, how can we account for the relationship between the modalized polite question and other types of polite constructions? Further, the results of the present study cannot be generalized to all epistemic modal of Korean and should be taken as preliminary indicators of the behavior of politeness when initiating a request. This will remain as my future agenda. 


\section{References}

Bak, Jae-Yeon. (2006). (A) Study on Modal Endings in Korean (written in Korean). Paju: Taehaksa

Blum-Kulka, Shoshana. (1987). Indirectness and politeness in requests: Same or different? Journal of Pragmatics 11, 131-146.

Brown, Lucian. (2015). Honorifics and politeness. In Lucian Brown and Jaehoon Yeon, eds., The Handbook of Korean Linguistic, 301-319. Wiley-Blackwell.

Brown, Penelope and Stephen C. Levinson. (1978). Universals in language usage: Politeness phenomena. In E.N. Goody, ed. Questions and Politeness: Strategies in Social Interaction, 56-311. Cambridge University Press.

Brown, Penelope and Stephen C. Levinson. (1987). Politeness: Some Universals in Language Usage. Cambridge University Press, Cambridge.

Bybee, Joan L., William Pagliuca and Revere Perkins. (1994). Evolution of Grammar: Tense, Aspect and Modality in the Language of the World. Chicago and London: The University of Chicago Press.

Byon, Andrew. (2006). The role of linguistic indirectness and honorifics in achieving linguistic politeness in Korean requests. Journal of Politeness Research 2(2), 247-276.

Chang, Sumi. (2014). Korean Honorific Speech Style Shift: Intra-Speaker Variables and Context. Ph.D. dissertation, University of Hawai'i at Manoa.

Dredge, Paul. (1983). What is politeness in Korean speech? Korean Linguistics 3, 21-32.

Faerch, Claus and Gabriel Kasper. (1989). Internal and External Modification in Interlanguage Request Realization. In S. Blum-Kulka, J. House and G. Kasper, eds., Cross-cultural pragmatics, 221-247. Norwood, NJ: Ablex.

Giannakidou, Anastasia. (1995). Subjunctive, habituality and negative polarity items. Semantics and Linguistic Theory 5, 94-111.

Giannakidou, Anastasia. (1999). Affective dependencies. Linguistics and Philosophy 22, 367-421. Giannakidou, Anastasia. (2013). Inquisitive assertions and nonveridicality. In Maria Aloni, Michael Franke, and Floris Roelofsen, eds., The Dynamic, Inquisitive, and Visionary Life of $\varphi, ? \varphi$ and Possibly $\varphi, A$ Festschrift for Jeroen Groenendijk, Martin Stokhof and Frank Veltman, 115-126.

Giannakidou, Anastasia and Alda Mari. (to appear). The Semantic Roots of Positive Polarity: Epistemic Modal Verbs and Adverbs. Linguistics and Philosophy.

Hara, Yurie and Christopher Davis. (2013). Darou as a deictic context shifter. In Kazuko Yatsushiro and Uli Sauerland, eds., Proceedings of Formal Approaches to Japanese Linguistics 6 (FAJL 6), 41-56. Cambridge, MA: MITWPL.

Hatfield, Hunter and Jee-Won Hahn. (2011). What Korean apologies require of politeness theory. Journal of Pragmatics 43(5), 1303-1317.

Holtgraves, Thomas. (2013). Language as Social Action: Social Psychology and Language Use. Psychology Press. 
Hwang, Juck-ryoon. (1975). Role of Sociolinguitics in Foreign Language Education with Reference of Korean and English Terms of Address and Levels of Deference. Ph.D. dissertation, University of Texas at Austin.

Hwang, Juck-ryoon. (1990). Deference versus politeness in Korean speech. International Journal of the Sociology of Language 82: Aspects of Korean Sociolinguistics, 41-55.

Jang, Youngjun. (1999). Two types of question and existential quantification. Linguistics 37, 847-869.

Jeon, Hye-Young. (2004). On the meaning of polite expressions in Korean (written in Korean). Korean Semantics 15, 71-91.

Jeong, Jin. (2013). Meaning acquisition of politeness of request speech act including '-keyss-' by Chinese learners of Korean (written in Korean). Korean Semantics 40, 415-439.

Kang, Arum. (2015). (In)definiteness, Disjunction and Anti-Specificity in Koran: A Study in the Semantics-Pragmatics Interface. Ph.D. dissertation, University of Chicago.

Kang, Arum and Suwon Yoon. (to appear). From inquisitive disjunction to nonveridical equilibrium: modalized questions in Korean. Linguistics.

Kim, Chonghyuck. (2010). Korean Question Particles Are Pronominals: A transparent Case of Representing Discourse Participants in the Syntax. Retrieved from: http://ling.auf.net/lingBuzz/ 001157/

Koo, Hyun Jung and Seongha Rhee. (2013b). On an emerging paradigm of sentence-final particles of discontent: A grammaticalization perspective. Language Sciences 37, 70-89.

Lee, Jungbok. (1999). On the strategic usage of Korean honorifics (written in Korean). Language Research 35(1), 91-122.

Márquez-Reiter, Rosina. (2002). A contrastive study of conventional indirectness in Spanish: Evidence from Peninsular and Uruguayan Spanish. Pragmatics 12(2), 135-151.

Rhee, Seongha. (2011). From politeness discourse strategy to grammar: Grammaticalization of stance markers. The Journal of Linguistic Science 59, 253-282.

Searle, John. (1975). Indirect Speech Acts. Syntax and semantics, In Peter Cole and Jerry L. Morgan, eds., 59-82. New York: NY: Academic Press.

Sohn, Ho-Min. (1986). Linguistic Expeditions. Seoul: Hanshin.

Sohn, Ho-Min. (1999). The Korean Language. Cambridge University Press.

Sohn, Ho-Min. (2013). Korean. Korea University Press.

Traugott, Elizabeth. (1982). From propositional to textual and expressive meanings: Some semantic-pragmatic aspects of grammaticalization. In W. P. Lehmann and Y. Malkiel, eds., Perspectives on Historical Linguistics, 245-271. Amsterdam: John Bengamins.

Traugott, Elizabeth. (1986). From polysemy to internal semantic reconstruction. In Nikiforidou, K. ed., Proceeding of the Twelfth Annual Meeting of the BLS. 539-550.

Traugott, Elizabeth. (1989). On the rise of epistemic meanings in English: An example of subjectification in semantic change. Language 65, 31-55.

Traugott, Elizabeth and Richard, Dasher. (2002). Regularity in Semantic Change. Cambridge: Cambridge University Press. 
Arum Kang

Research Professor

The Research Institute of Language and Information

Korea University

Seokwan 109A, Anam-ro 145, Seongbuk-gu, Seoul 02841, Korea

E-mail: arkang@korea.ac.kr

Received: March 1, 2018

Accepted: July 19, 2018 